Portland State University

PDXScholar

Civil and Environmental Engineering

Undergraduate Honors Theses

Fall 2017

\title{
Elution Tailing of Nonaqueous Phase Liquids in Porous Media
}

Louisa Orr

Portland State University

Follow this and additional works at: https://pdxscholar.library.pdx.edu/cengin_honorstheses

Part of the Environmental Engineering Commons, and the Environmental Monitoring Commons Let us know how access to this document benefits you.

\section{Recommended Citation}

Orr, Louisa, "Elution Tailing of Nonaqueous Phase Liquids in Porous Media" (2017). Civil and Environmental Engineering Undergraduate Honors Theses. 10.

https://doi.org/10.15760/honors.484

This Thesis is brought to you for free and open access. It has been accepted for inclusion in Civil and Environmental Engineering Undergraduate Honors Theses by an authorized administrator of PDXScholar. Please contact us if we can make this document more accessible: pdxscholar@pdx.edu. 


\title{
Elution Tailing of Nonaqueous Phase Liquids in Porous Media
}

by Louisa Orr

\author{
Portland State University \\ BACHELOR OF SCIENCE IN \\ ENVIRONEMENTAL ENGINEERING
}

Thesis Advisor:

Gwynn Johnson, Ph.D. 


\section{Acknowledgements}

This meta study was facilitated by the work of other researchers. In particular, the author would like to thank Dr. Gwynn Johnson for guiding and advising the production of this work. We all stand on the shoulders of giants. 


\begin{abstract}
A variety of porous media were studied to characterize contaminant dispersion over time. This work looked at a compilation of previously published studies to investigate the dependence of long term elution tailing trends on particular soil characteristics. Recession curve analysis was conducted on existing dispersed contaminant literature, to yeild the low-concentration recession constant $(\mathrm{K})$. The $\mathrm{R}^{2}$ values correlating the soil properties to contaminant concentration ranged from 0.12494 to 0.95429 . The low-concentration recession constant $(\mathrm{K})$ values ranged from 0.97454070 .9999988 . The relationship between $\mathrm{K}$ and the soil properties porosity, organic carbon, and fines fraction is increasing. Bulk density and the partitioning coefficient exhibit a decreasing relationship with $\mathrm{K}$. The observed trends may serve as a take off for further research.
\end{abstract}




\section{Table of Contents}

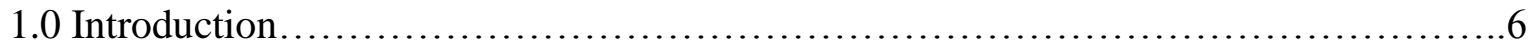

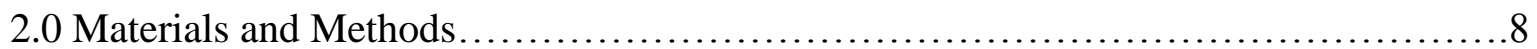

3.0 Results................................................................... 9

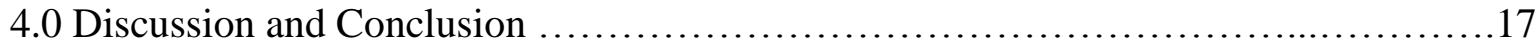




\section{List of Tables}

Table 1: Summary of soil characteristics from previously conducted studies.

Table 2: Partitioning coefficients, K, of linearly regressed recession curve data.

\section{List of Figures}

Figure 1: Recession curve analysis of Culver's experiment 1.

Figure 2: Recession curve analysis of Culver's experiment 2.

Figure 3: Recession curve analysis of Thorbjarnarson experiment A.

Figure 4: Recession curve analysis of Thorbjarnarson experiment B.

Figure 5: Recession curve analysis of Thorbjarnarson experiment $\mathrm{C}$.

Figure 6: Recession curve analysis of Brusseau's aged 4 year data.

Figure 7: Recession curve analysis of Brusseau's 100 pore volume data.

Figure 8: Recession curve analysis of Brusseau's 30 year.

Figure 9: Recession curve analysis of Johnson's 2009 study: Experiment A.

Figure 10: Recession curve analysis of Johnson's 2009 study: Experiment B.

Figure 11: Recession curve analysis of Johnson's 2009 study: Experiment C.

Figure 12: Recession curve analysis of Johnson's 2003 study.

Figure 13: Recession curve analysis of Russo's Eustis data.

Figure 14: Recession curve analysis of Russo's Mt. Lemmon data.

Figure 15: Recession curve analysis of Russo's Borden data. 


\section{INTRODUCTION}

Modeling the transport and fate of chlorinated solvents in the subsurface environment can yield information regarding the location and concentration of problematic/recalcitrant constituents. Remediation of contaminants begins with tracking their migration. This cannot be done without an understanding of transport phenomena and dispersion mechanisms often associated with physical and chemical heterogeneities in subsurface systems. The transport of aqueous phase constituents through soils and groundwater have been widely studied, but the mechanisms responsible for long-term transport and fate behavior remain unknown.

Movement of contaminants can be a function of $\mathrm{pH}$, temperature, densities, and viscosities. The total mass and long-term fate of contaminants in soil is often a function of diffusion, dispersion, sorption, volatilization and chemical and biological transformations most effectively modeled by the advection dispersion equation (Fetter, 1993). The advection dispersion equation (ADE) for one dimensional flow models solute spread due to flow velocity with advection, molecular and mechanical dispersion, and diffusion (random particle movement from areas of higher concentration to lower concentration).

The characteristics of contaminants and the affected environments combine to determine the overall spread of contaminant plumes. Many of these interactions and their results can be approximated in a lab setting, but the physical and chemical heterogeneity of in situ conditions leads to a great deal of uncertainty in predicting contaminant spread. These uncertainties are minimized as additional research is conducted to further our understanding of subsurface environments.

The concentration of a contaminant as a function of distance from the source or time since release can be quantified using the advection dispersion equation. The resultant breakthrough curve graphically represents overall contaminant transport behavior. For example, breakthrough curves associated with the complete dissolution of NAPLs characteristically yield early-stage steady state aqueous-phase concentrations, equal to the contaminant's aqueous solubility. During this stage of dissolution, constituents of the NAPL are dissolving into groundwater, with concentration gradients maintaining that maximum aqueous concentration. As the source of 
contaminant becomes depleted (i.e., as the NAPL phase diminishes), the measured concentration in solution enters a dynamic state, exhibiting rate-limited transport behavior. After a period of marked decline, the contaminant concentration commonly reaches a low-concentration plateau. Rate-limited mass transfer drives this phase known as the elution tail. As discussed in Johnson et al. (2003), this low-concentration plateau often presents significant elution tailing controlled by rate-limited sorption/desorption phenomena.

The physical and/or chemical properties of natural porous media responsible for this commonly observed low-concentration asymptotic behavior are not well understood. An area of particular interest is the impact of varying levels of organic carbon content in affected soils. The objective of this project is to investigate chlorinated solvent elution tailing from various natural porous media. Project goals include using a simple recession curve analysis of low-concentration trichloroethene elution tailing reported in the literature to qualify the physical and/or chemical property(s) potentially responsible for the reported recalcitrant behavior. 


\section{METHODS}

The advection dispersion equation (ADE) for one dimensional transport through porous media gives the change in concentrations over time as a function of the hydrodynamic dispersion coefficient $\left(D_{L}\right)$, constituent concentration $(C)$, average linear porewater velocity $(v)$, bulk soil density $\left(\rho_{b}\right)$, volumetric moisture content $(\theta)$, and the amount of solute sorbed per unit weight of solid $\left(C^{*}\right)$.

$$
\frac{\partial C}{\partial t}=D_{L} \frac{\partial^{2} C}{\partial x^{2}}-v \frac{\partial C}{\partial x}-\frac{\rho_{b}}{\theta} \frac{\rho C^{*}}{\partial t}+\left(\frac{\partial C}{\partial t}\right)_{r x n}
$$

wherein reactions (excluding sorption/desorption) impacting a contaminant's transport and fate can be accounted for with the final " $r x n$ " term. A simple linear expression often used to define the sorbed-phase concentration $\left(C^{*}\right)$ is shown in Equation (2):

$$
C^{*}=K_{d} C
$$

Application of the ADE to describe contaminant transport often requires fitting of the ADE equation to measured breakthrough data. Without complete characterization of the physical and chemical heterogeneities of the respective porous media, the resulting "fitted" parameters $\left(D_{L}, v\right.$, and $K_{d}$ ) become "lumped-term" parameters with the effects of physical and chemical mechanisms contributing to the overall transport and fate behavior lumped together. This limits the ability to qualify those discrete mechanisms controlling contaminant transport and fate through porous media.

The overall goal of this project was to investigate the application of a simple first order model based on recession curve analysis to low-concentration elution tailing reported for the transport of trichloroethene in natural porous media. Project objectives include analyzing lowconcentration elution data reported in the literature. Each study reported trichloroethene aqueous phase concentration data as a function of time or nondimensional time (i.e., pore volume). Recession curve analysis was conducted on each data set. The data was discretized by pulling Cartesian coordinates off figures representing the data collected. These data points were cataloged and analyzed using a first order recession curve equation as shown in Equation (3): 


$$
C=C_{0} K^{t}
$$

where the temporally variable contaminant concentration $(C)$ is expressed as a function of constant $(K)$ and the initial concentration $\left(C_{o}\right)$. Rearranging and integrating this expression, Equation 3 can be linearized as follows:

$$
\log C=\log C_{0}+t \log K \quad(4)
$$

The slope of a plot of $\log C$ versus time yields $\log K$. From this, the low-concentration recession constant, $K$, can be determined. Each set of discretized contaminant concentration data was linearized and plotted accordingly to determine the values for $K$. This data can be compared to the experiments' soil column data to establish potential trends relating column composition to partitioning behaviors. 


\section{RESULTS}

Multiple studies reporting trichloroethene low-concentration elution data were used in this analysis. For example, Culver et al. (1997) conducted a study of the elution of trichloroethene from long-term contaminated natural soils. Data from a field tracer test in a stratified aquifer was collected by researchers Thorbjarnarson and Mackay (1995). Brusseau et al. (2012) studied the impact of contact time on sorption/desorption and long-term, low-concentration elution tailing in Eustis sandy soil. Russo et al. (2010) reports asymptotic elution tails of trichloroethene in multiple natural porous media (e.g., Eustis, Mt. Lemmon, and Borden). Johnson et al. (2003) includes the results of long-term elution tailing of trichloroethene in a sandy aquifer material. Elution tailing data comparing the impacts of contact time on sorption/desorption in a sandy aquifer materials has been reported in Johnson et al. (2009). A summary of these experimental findings reported in the literature including soil properties and sorption coefficients in presented in Table 1.

Table 1: Summary of soil characteristics from previously conducted studies, where $f_{\text {oc }}$ is the fraction of organic carbon content and $K_{d}$ is the partitioning coefficent

\begin{tabular}{|c|c|c|c|c|c|c|}
\hline & & Fines Fraction & $f_{o c}(\%)$ & Porosity & Bulk Density $\left(\mathrm{g} / \mathrm{cm}^{3}\right)$ & $K_{d}(\mathrm{~mL} / \mathrm{g})$ \\
\hline Culver & & & 1.04 & 0.38 & 1.61 & 0.69 \\
\hline Thorbjarnarson & & $6.8-8.7$ & & 0.31 & 1.75 & $0.00-0.21$ \\
\hline Brusseau & & 4 & 0.038 & 0.33 & 1.76 & \\
\hline \multirow[t]{3}{*}{ Johnson (Chemosphere) } & A & 4.3 & 0.03 & & 1.72 & \\
\hline & B & 1.1 & 0.03 & & 1.56 & \\
\hline & $\mathrm{C}$ & 2.6 & 0.03 & & 1.81 & \\
\hline Johnson (WRR) & & 2.6 & 0.045 & & 1.81 & \\
\hline \multirow[t]{3}{*}{ Russo } & Eustis & 4 & 0.38 & 0.27 & 1.69 & 0.3 \\
\hline & Mt. Lemmon & 11 & 2.7 & 0.17 & 1.45 & 3.4 \\
\hline & Borden & 3.8 & 0.03 & 0.21 & 1.74 & 0.1 \\
\hline
\end{tabular}

The trend lines in the following figures are shown for illustrative purposes only; they are not meant to indicate data points. The study by Culver et al. contained 2 data sets, experiments 1 and 2, seen in Figures 1 and 2, respectively. The linear regression of the data gives the slope $=\log \mathrm{K}$ for each experiment. The $\mathrm{R}^{2}$ values for the regression fit are 0.51989 and 0.64803 for experiments 1 and 2 . 


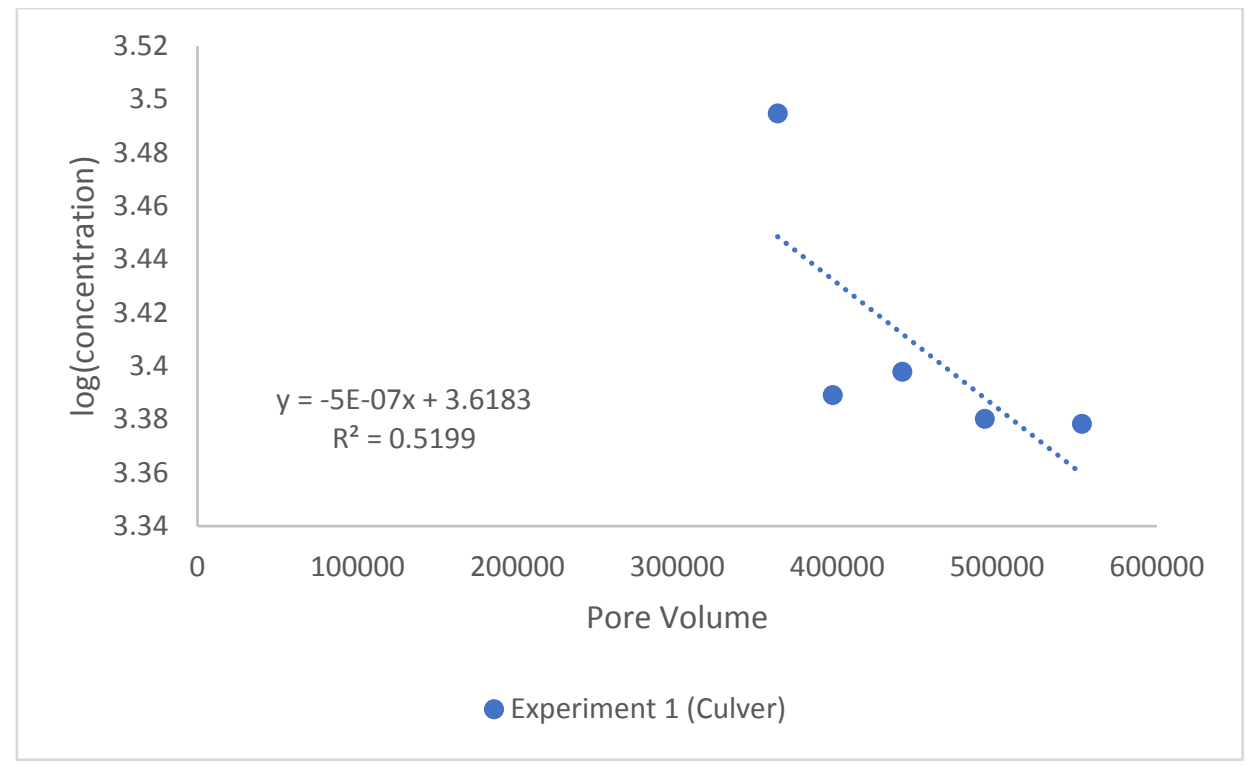

Figure 1: Recession curve analysis of Culver's experiment 1.

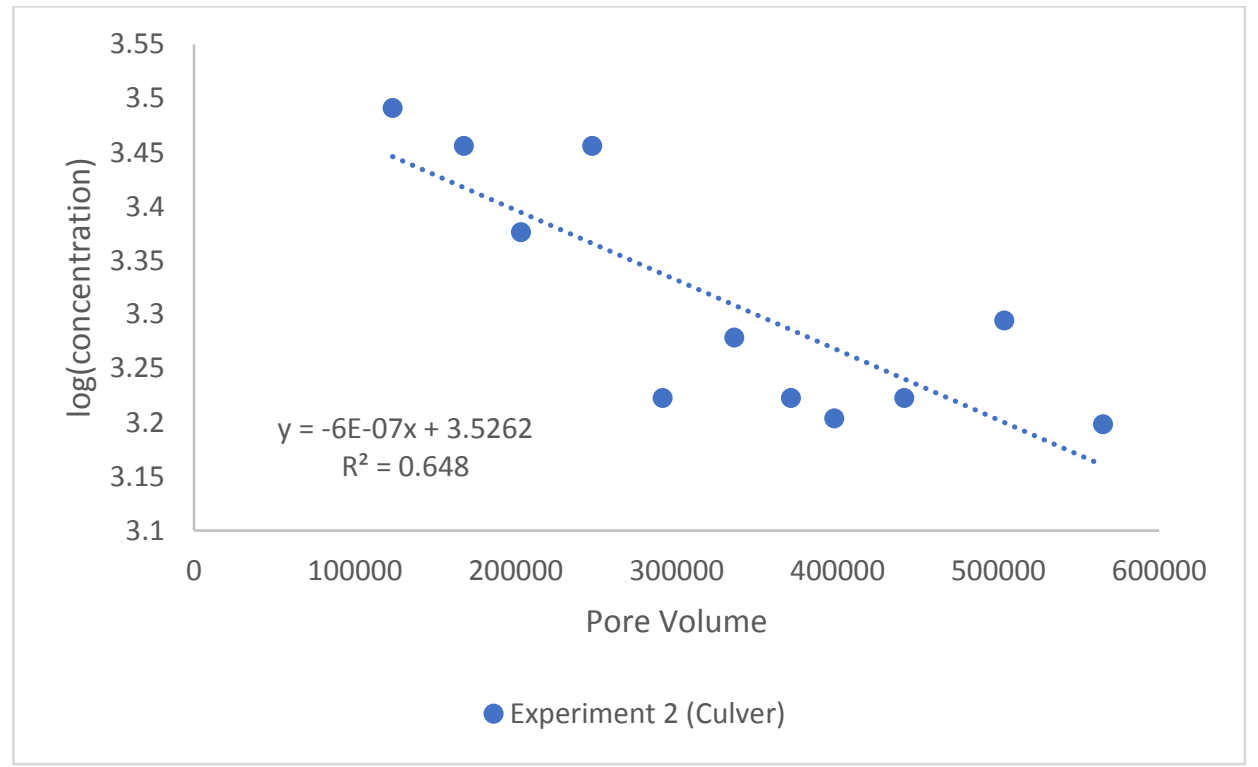

Figure 2:Recession curve analysis of Culver's experiment 2.

Linear regression analysis of the Thorbjarnarson et al. data did not yield a strong correlation for experiment 1 with an $R^{2}$ value of 0.1143 ; experiments 2 and 3 were better fits were $R^{2}=0.63236$ and 0.95429, see Figures 3-5. 


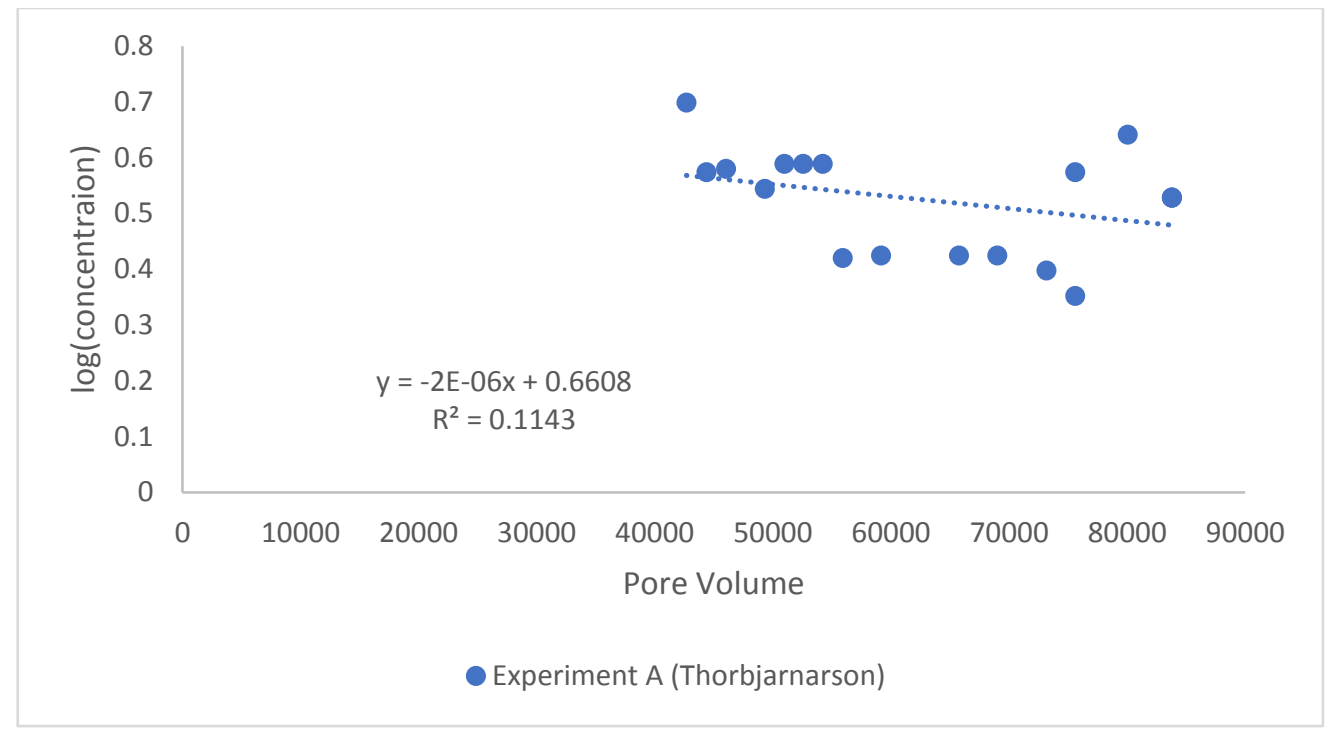

Figure 3: Recession curve analysis of Thorbjarnarson experiment A data.

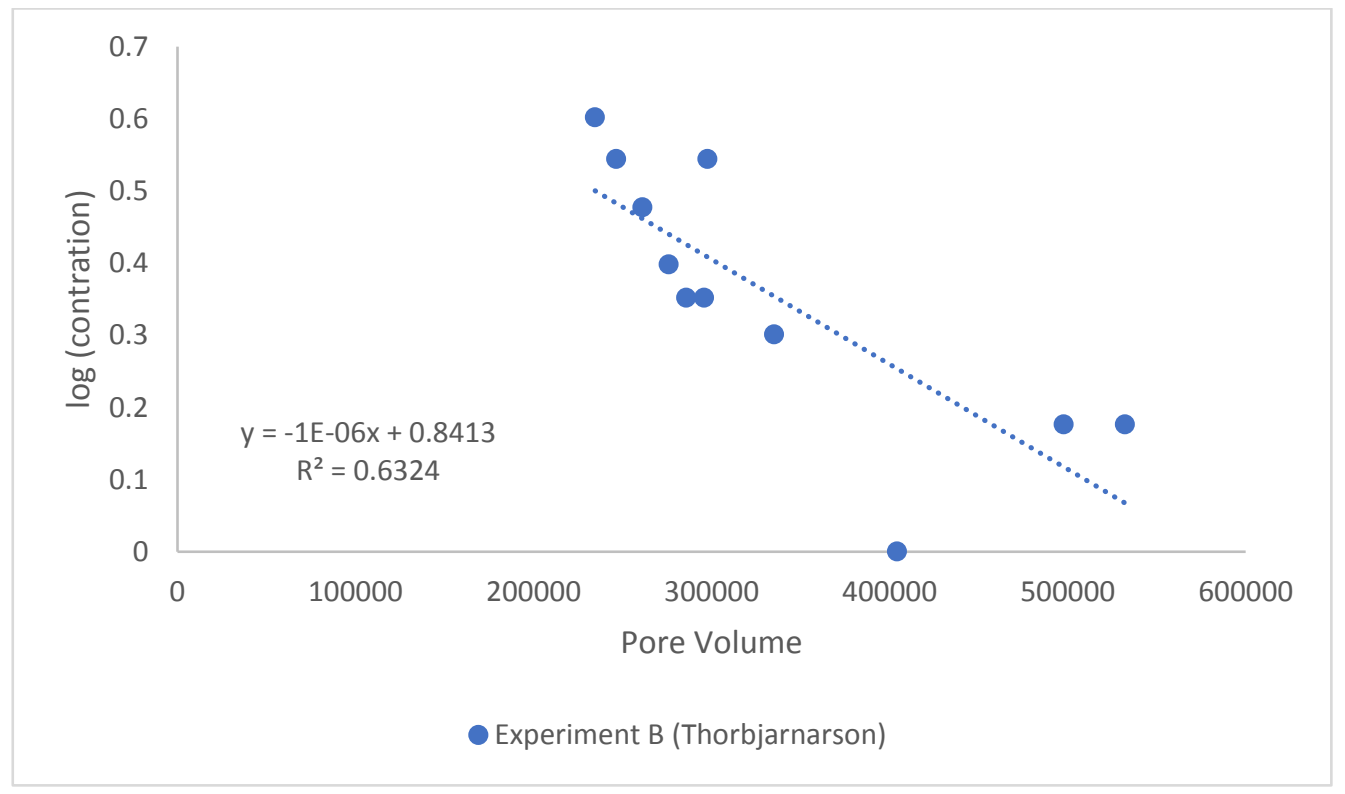

Figure 4: Recession curve analysis of Thorbjarnarson experiment B data 


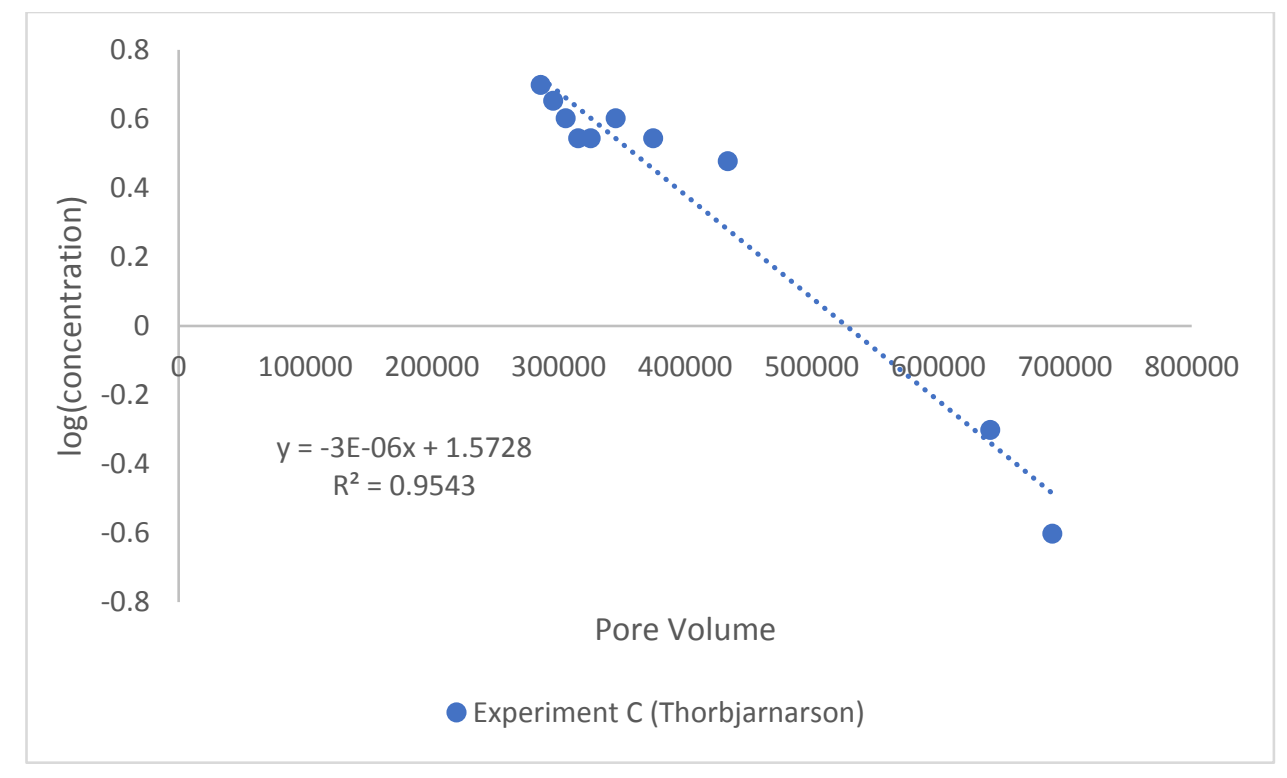

Figure 5: Recession curve analysis of Thorbjarnarson experiment C data.

The 4 year aged and 100 pore volume data pulled from Brusseau et al. showed a poor fit when the $\log$ of contaminant concentration was regressed against pore volumes, while the 30 day aged data showed a strong correlation. The $\mathrm{R}^{2}$ values were $0.22672,0.11607$, and 0.91655 , respectively. See regressed data and trend lines in Figures 5-7.

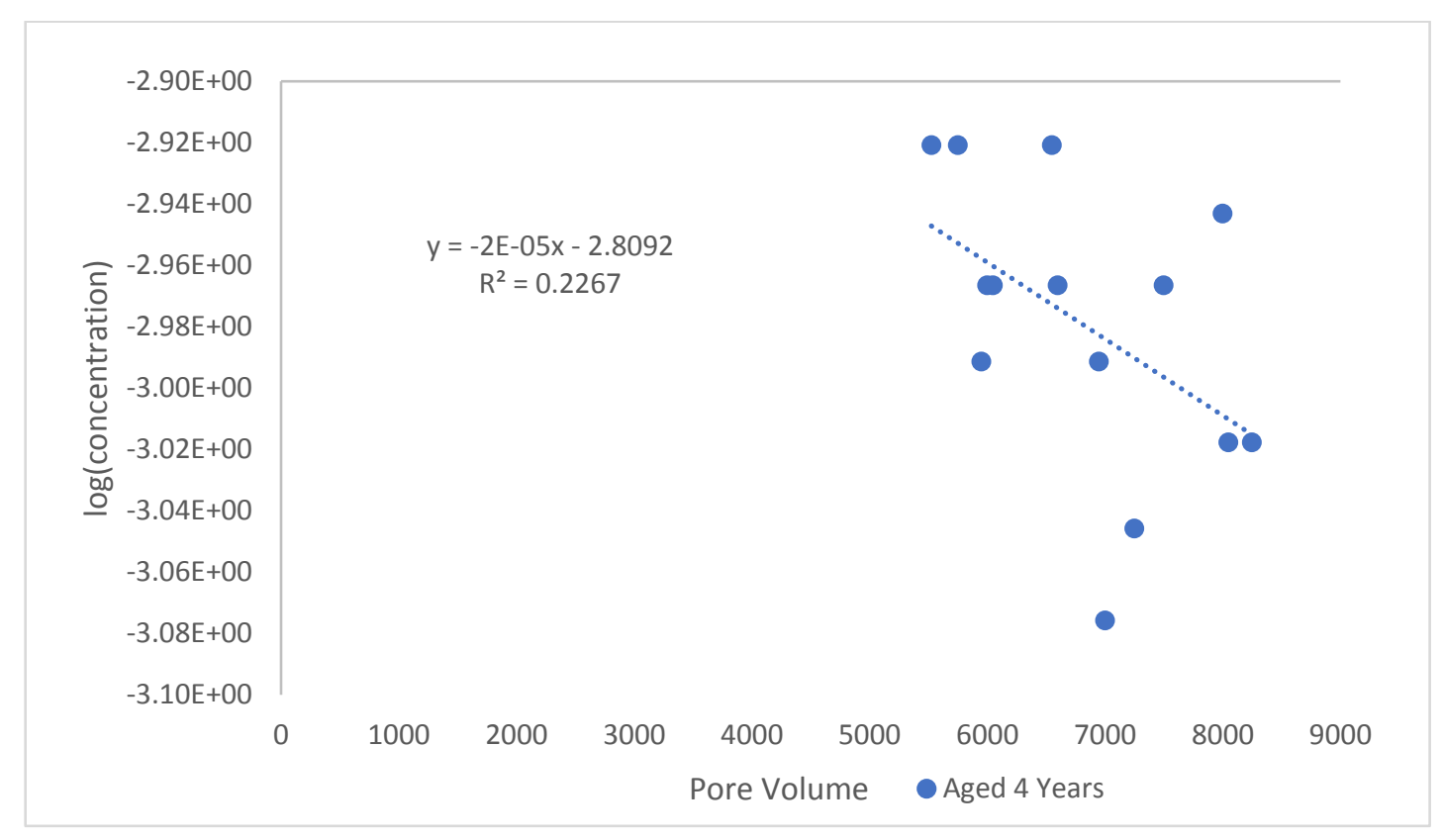

Figure 6: Recession curve analysis of Brusseau's aged 4 year data. 


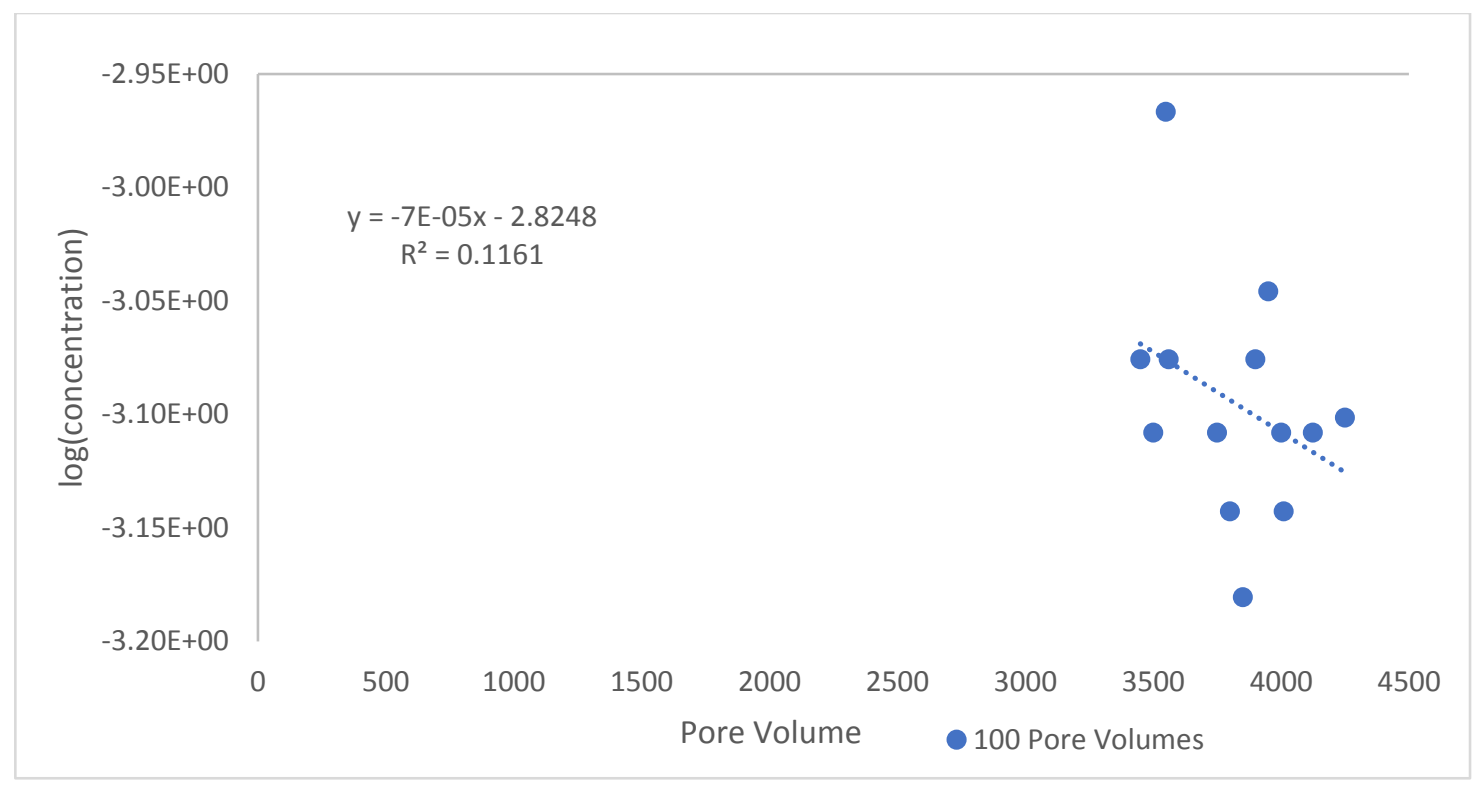

Figure 7: Recession curve analysis of Brusseau's 100 pore volume data.

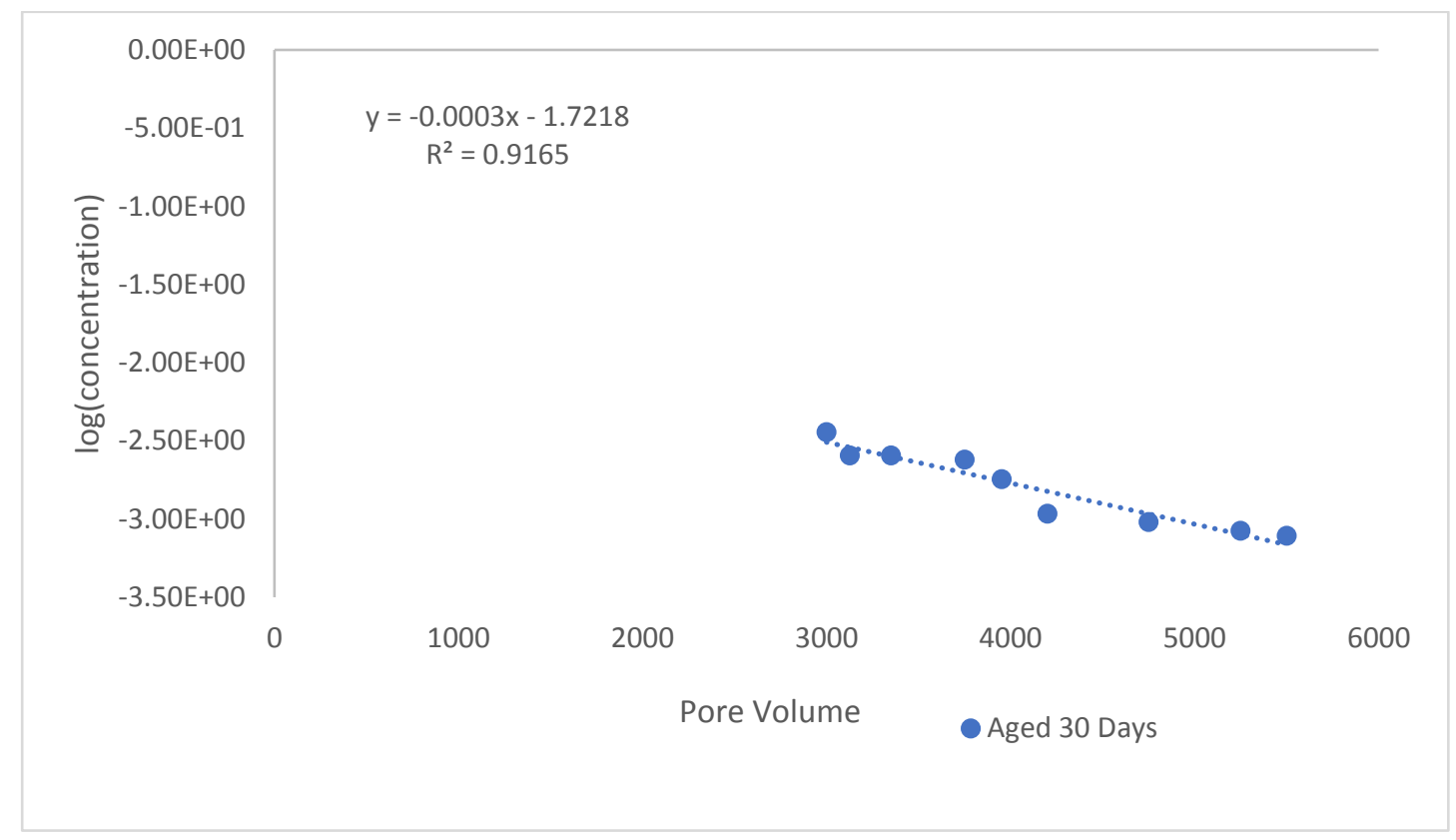

Figure 8: Recession curve analysis of Brusseau's aged 30 day data.

The 2009 Johnson study published in Chemosphere contained 3 sets of data: experiments A, B, and $\mathrm{C}$. The $\mathrm{R}^{2}$ values from linear regression analysis were $0.68899,0.01494$, and 0.33408 for experiments A, B, and C. Figures 8-10 show the plotted data. Experiment B is unique in that it is the only set of data to show an increasing trend between concentration and time/pore volume. 


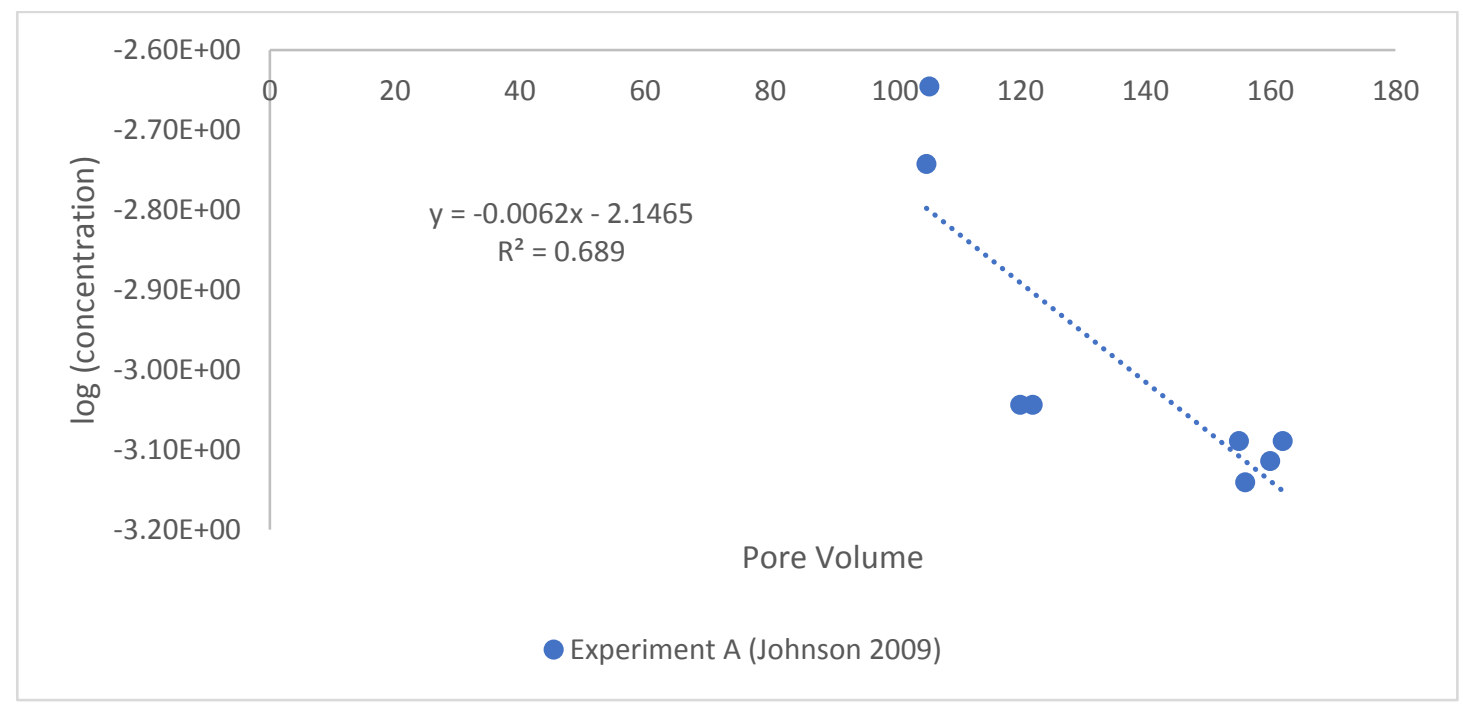

Figure 9: Recession curve analysis of Johnson's 2009 study: Experiment A.

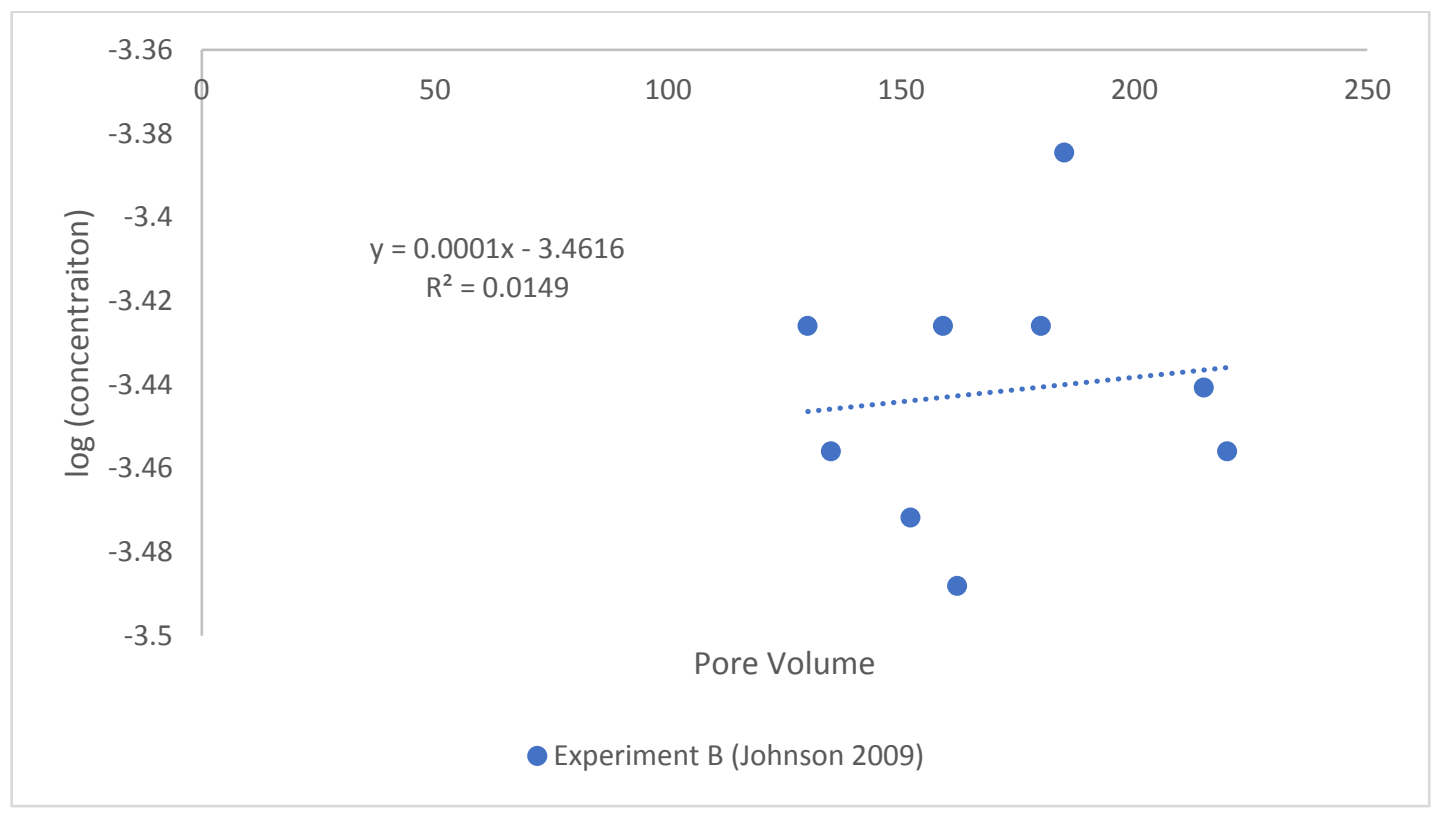

Figure 10: Recession curve analysis of Johnson's 2009 study: Experiment B. 


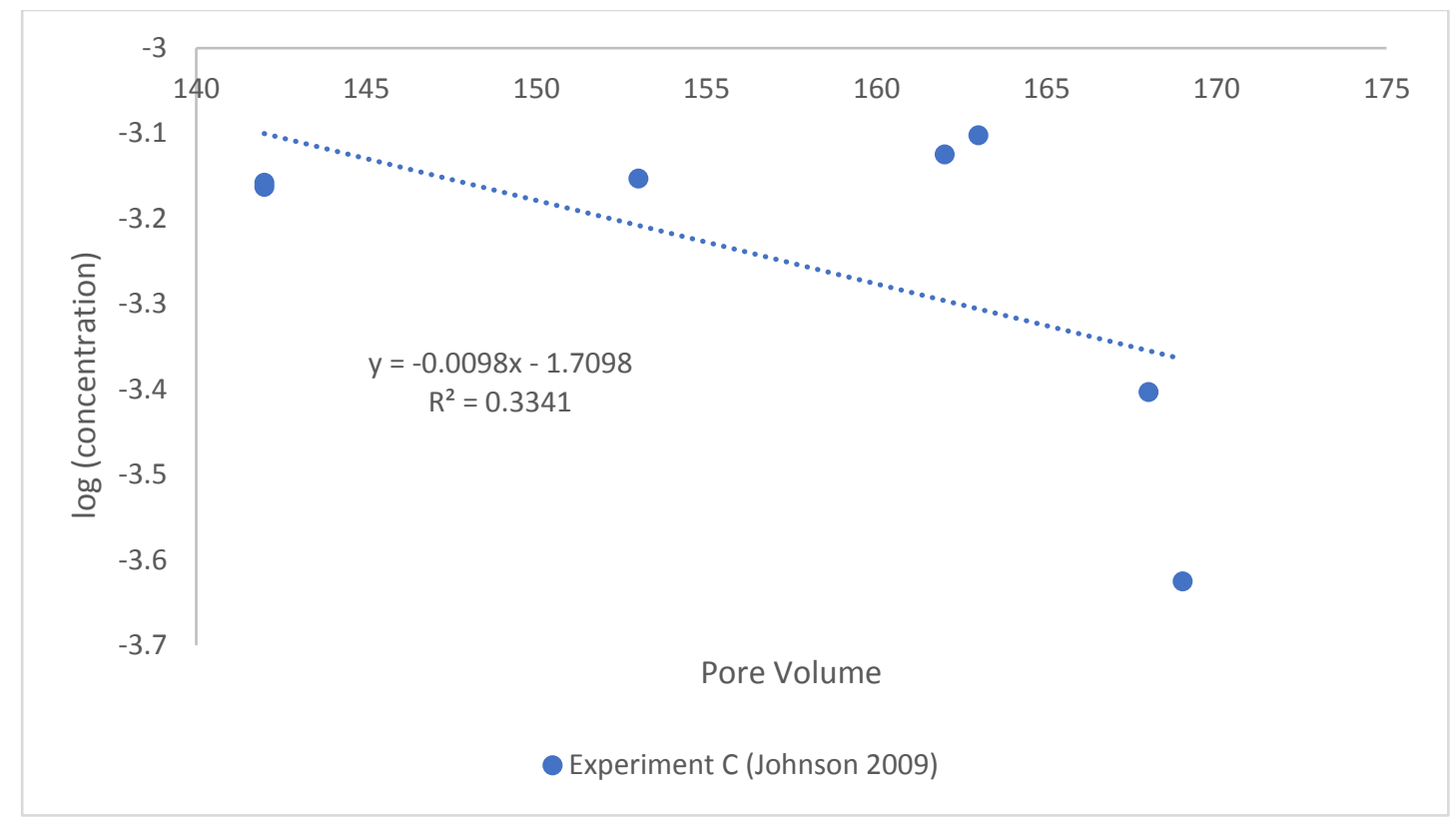

Figure 11: Recession curve analysis of Johnson's 2009 study: Experiment C.

The 2003 Johnson study published in Water Resources Research contained 1 experiment used here. The $\mathrm{R}^{2}$ value of the linear regression was 0.74981 ; see Figure 12 for the plotted data.

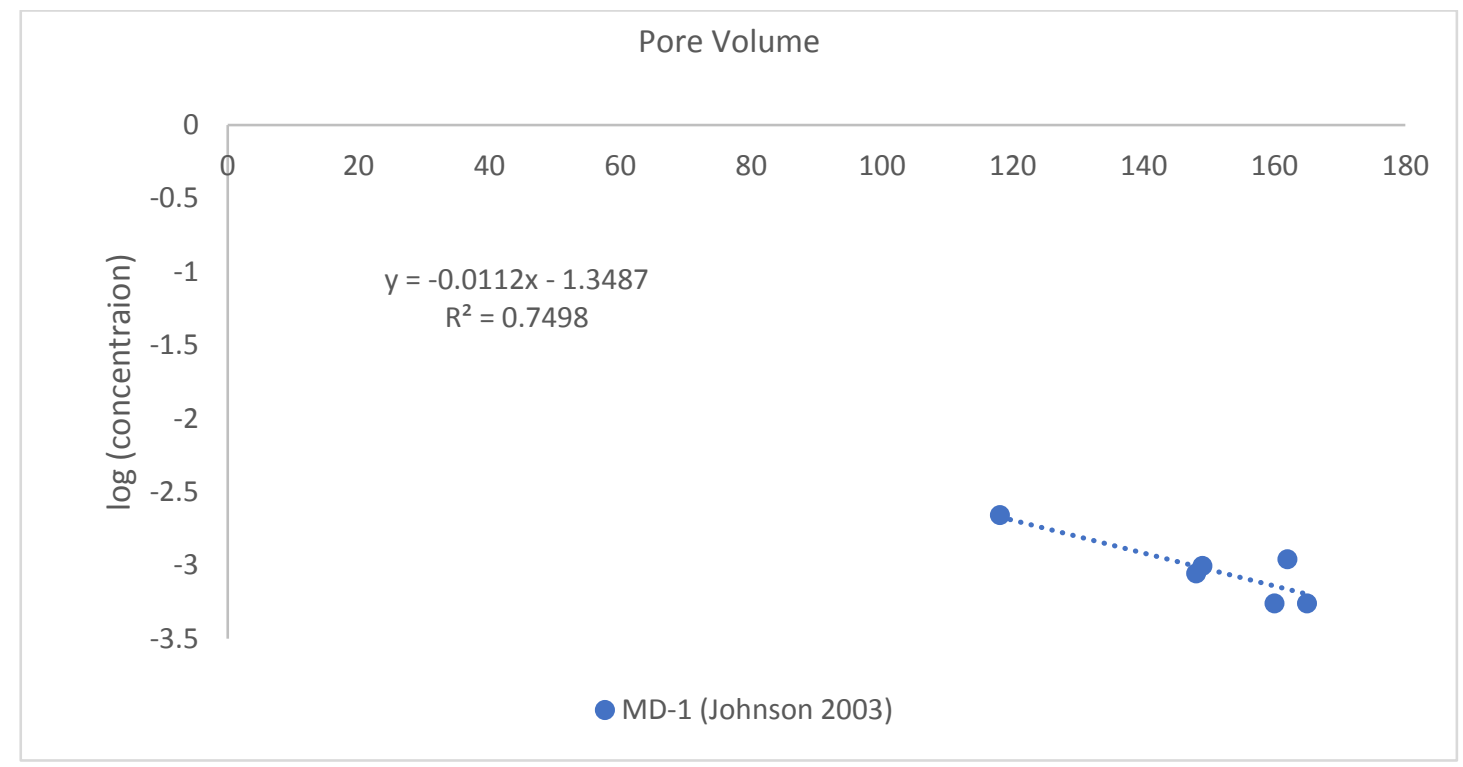

Figure 12: Recession curve analysis of Johnson's 2003 study.

The Russo study contained 3 data sets which yielded the following $\mathrm{R}^{2}$ values upon linear regression analysis: Eustis $\left(R^{2}=0.19759\right)$, Mt. Lemmon $\left(R^{2}=0.7558\right)$, and Borden $\left(R^{2}=\right.$ 
0.79131). Each data set showed a decreasing trend with log scaled relative concentration versus pore volume, see Figures 13-15.

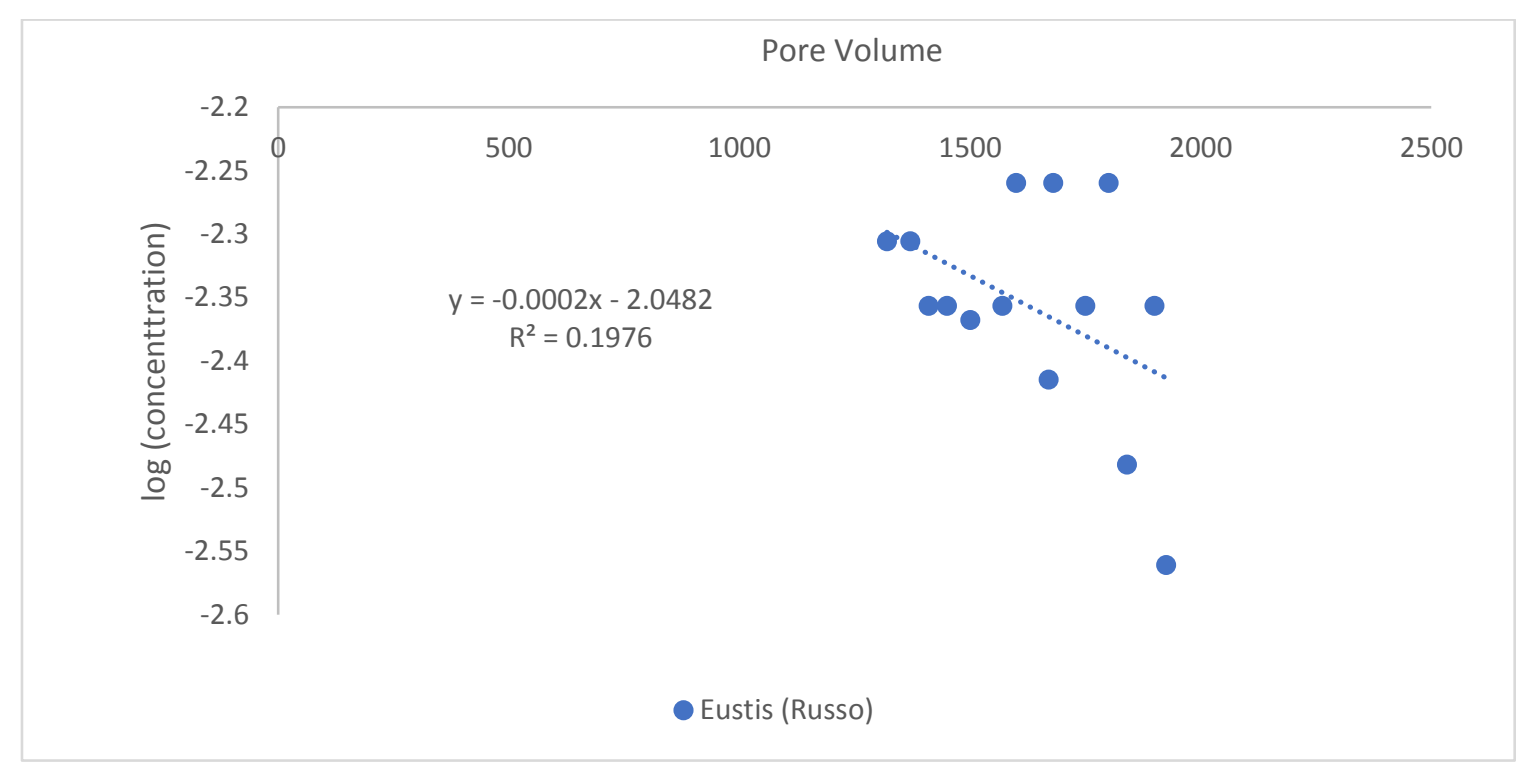

Figure 13: Recession curve analysis of Russo's Eustis data.

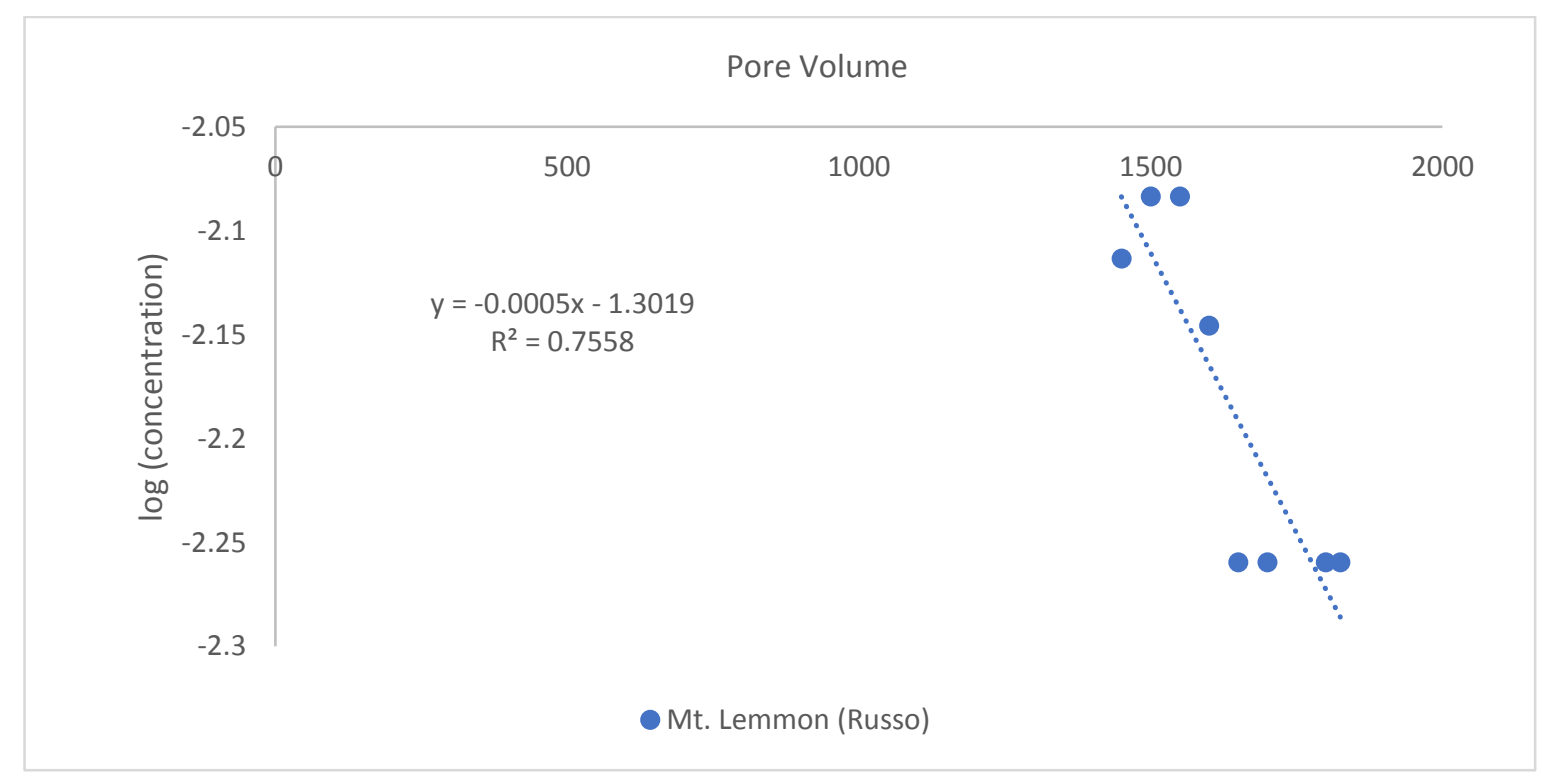

Figure 14: Recession curve analysis of Russo's Mt. Lemmon data. 


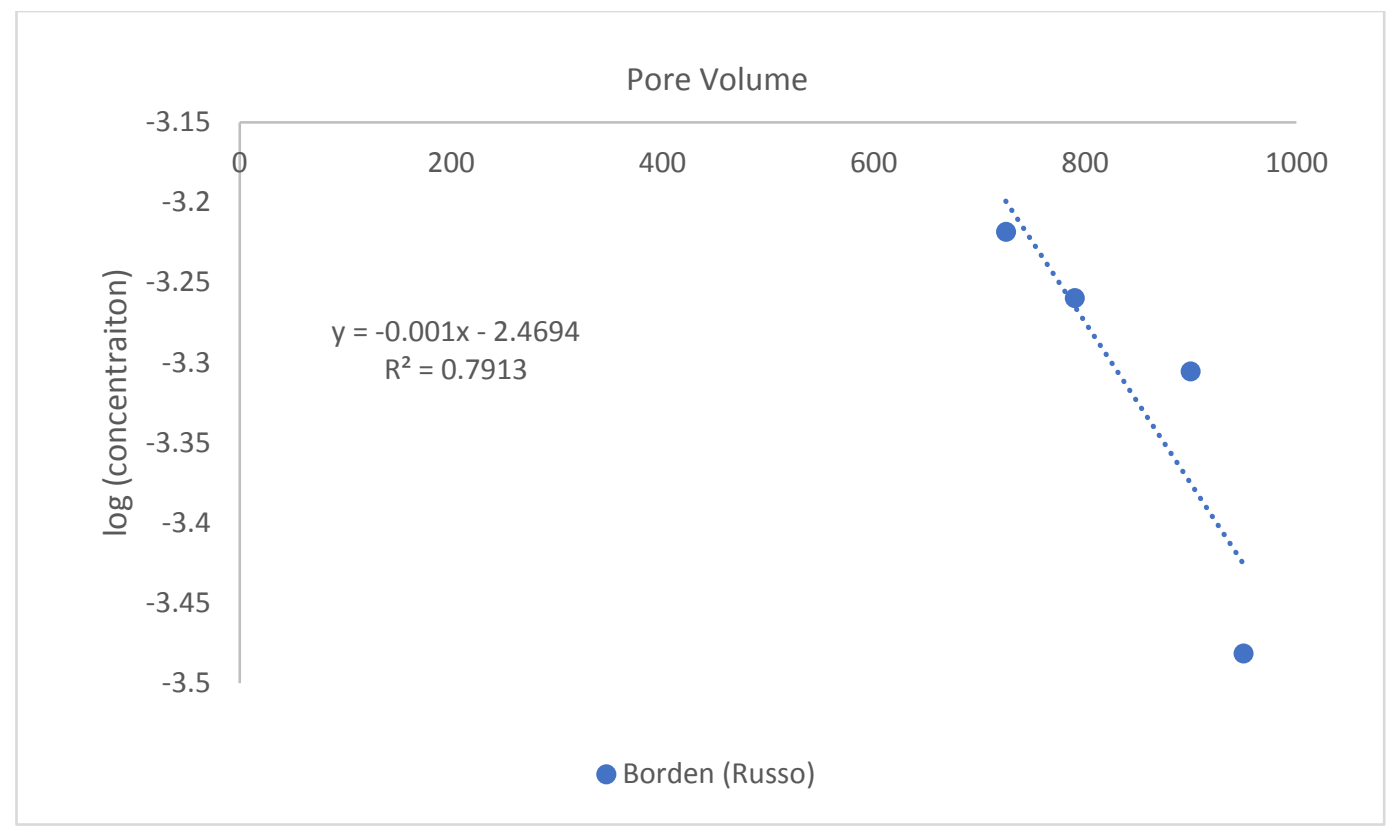

Figure 15: Recession curve analysis of Russo's Borden data.

The low-concentration recession constant, $\mathrm{K}$, was found according to Equation 3. Results from each data set are seen in Table 2 . 
Table 2: Partitioning coefficients, $K$, of linearly regressed recession curve data

\begin{tabular}{|c|c|c|}
\hline Existing Study & \multicolumn{2}{|c|}{ K } \\
\hline \hline \multirow{2}{*}{ Culver } & 1 & 0.9999988 \\
& 2 & 0.9999986 \\
\hline \multirow{3}{*}{ Thorbjarnarson } & A & 0.9999954 \\
& B & 0.9999977 \\
\cline { 2 - 3 } & C & 0.9999931 \\
\hline \multirow{2}{*}{ Brusseau } & Aged 4 years & 0.9999539 \\
& 100 Pore Volumes & 0.9998388 \\
\cline { 2 - 3 } & Aged 30 days & 0.9993094 \\
\hline \multirow{2}{*}{ Johnson (Chemosphere) } & A & 0.9858254 \\
& B & 0.9997697 \\
& C & 0.9776874 \\
\hline Johnson (WRR) & & 0.9745407 \\
\hline \multirow{2}{*}{ Russo } & Eustis & 0.9995396 \\
& Mt. Lemmon & 0.9988494 \\
\cline { 2 - 3 } & Borden & 0.9977001 \\
\hline
\end{tabular}

These low-concentration recession constants were compared to known soil column characteristics. In all cases, regardless of the soil characteristic of interest, the $\mathrm{K}$ values are clustered close to $\mathrm{K}=1$. Figure 16 shows the fraction of fine soil particles versus $\mathrm{K}$. There is a slight increasing trend illustrated by the trendline where $\mathrm{R}^{2}=0.15903$. Figure 17 shows a weak $\left(\mathrm{R}^{2}=0.05747\right)$ decreasing trend between the partitioning coefficient and K. Figure 18 displays the increasing relationship between porosity and $\mathrm{K}$; the correlation is not strong with $\mathrm{R}^{2}=$ 0.5849. Figure 19 shows the relationship between the soils' organic carbon content and K. The correlation using these data is very weak: $\mathrm{R}^{2}=0.08732$ 


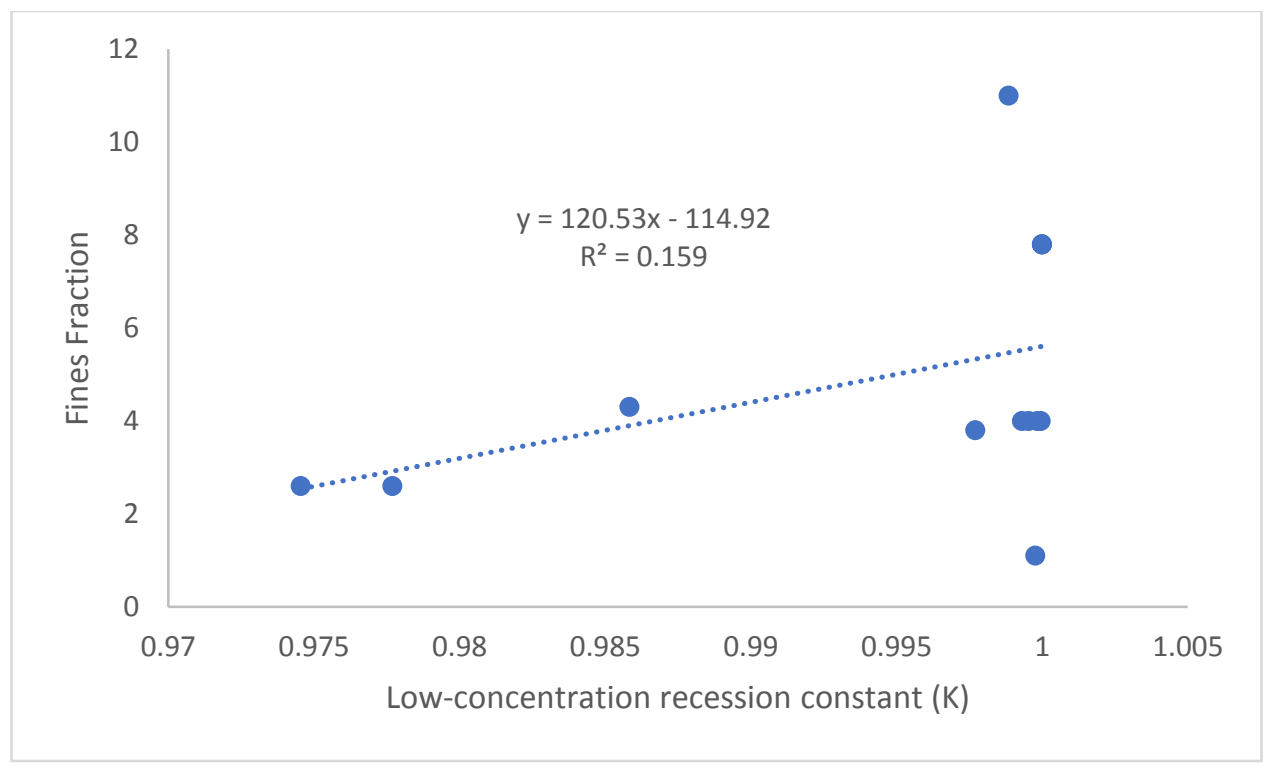

Figure 16: Fines fraction of the experiments' soils versus the low-concentration recession constant.

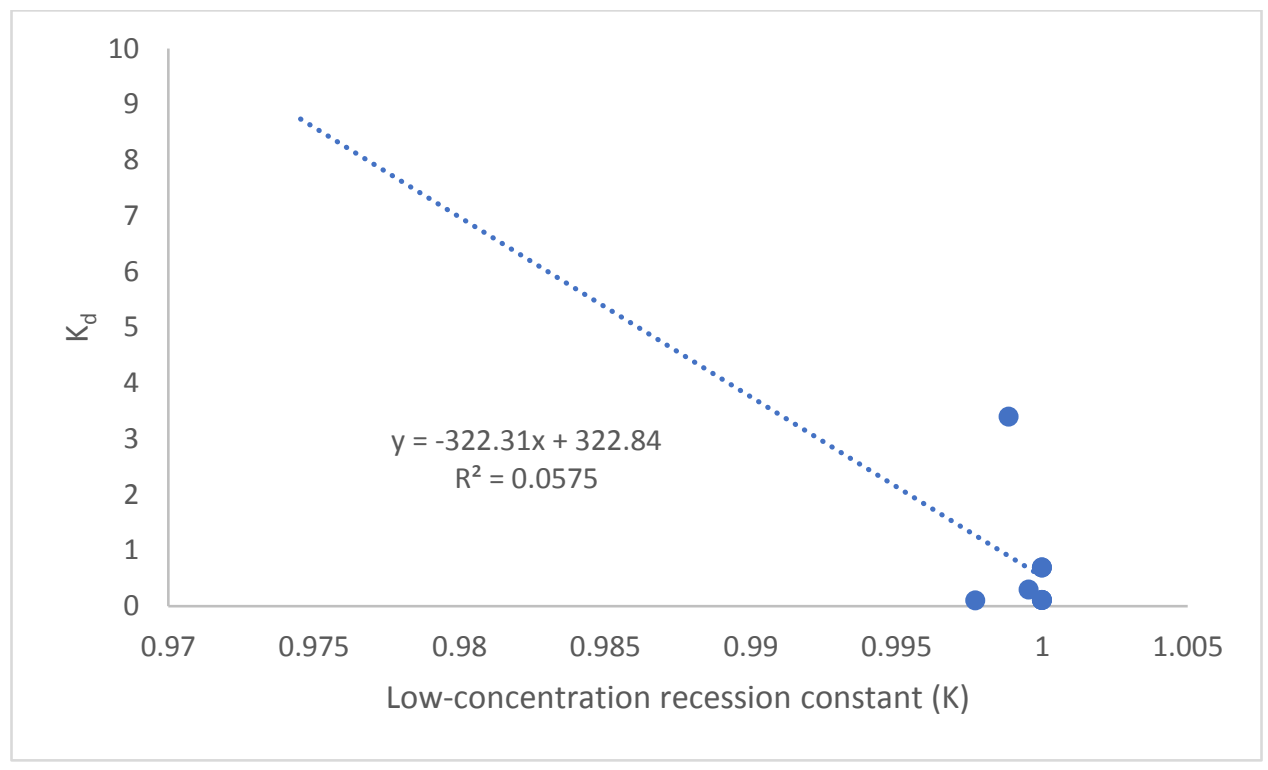

Figure 17: Known partitioning coefficients from the experiments' soils versus the low-concentration recession constant. 


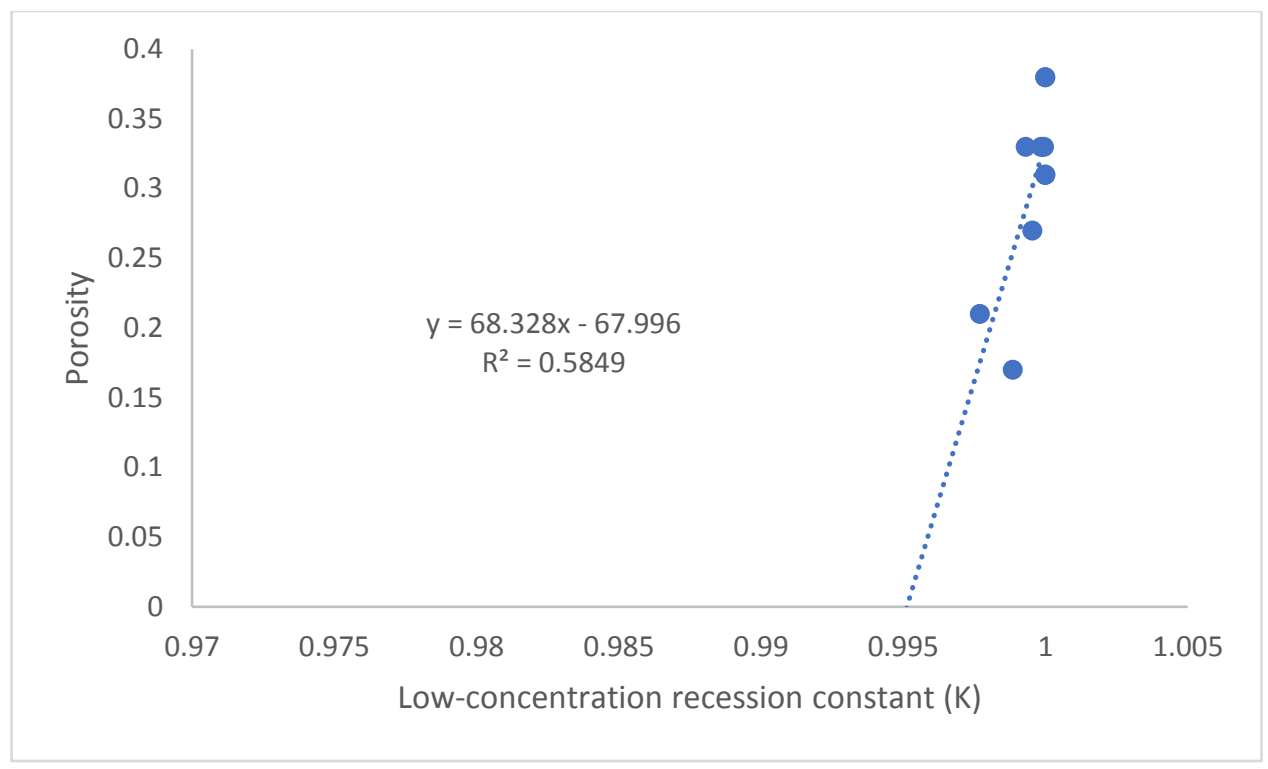

Figure 18: Soil porosity of the experiments' soils versus the low-concentration recession constant.

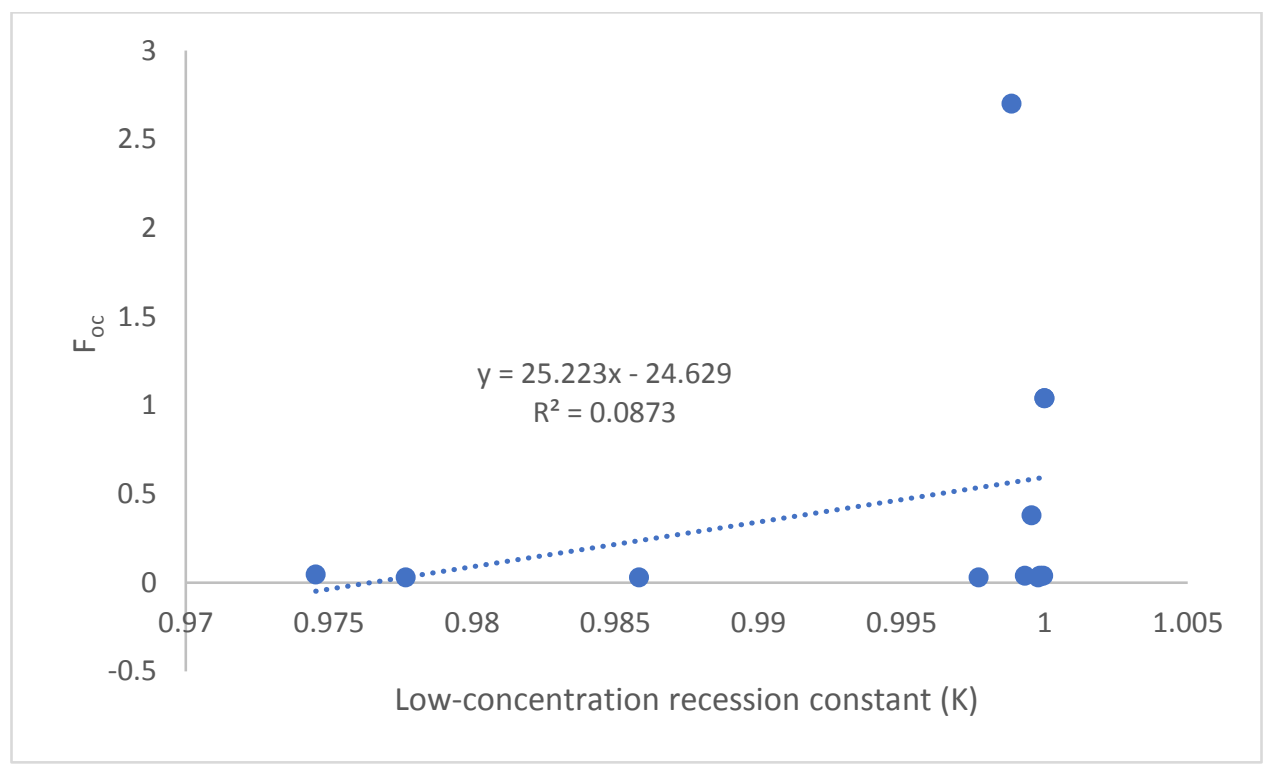

Figure 19: Organic content of experiments' soils versus the low-concentration recession constant. 


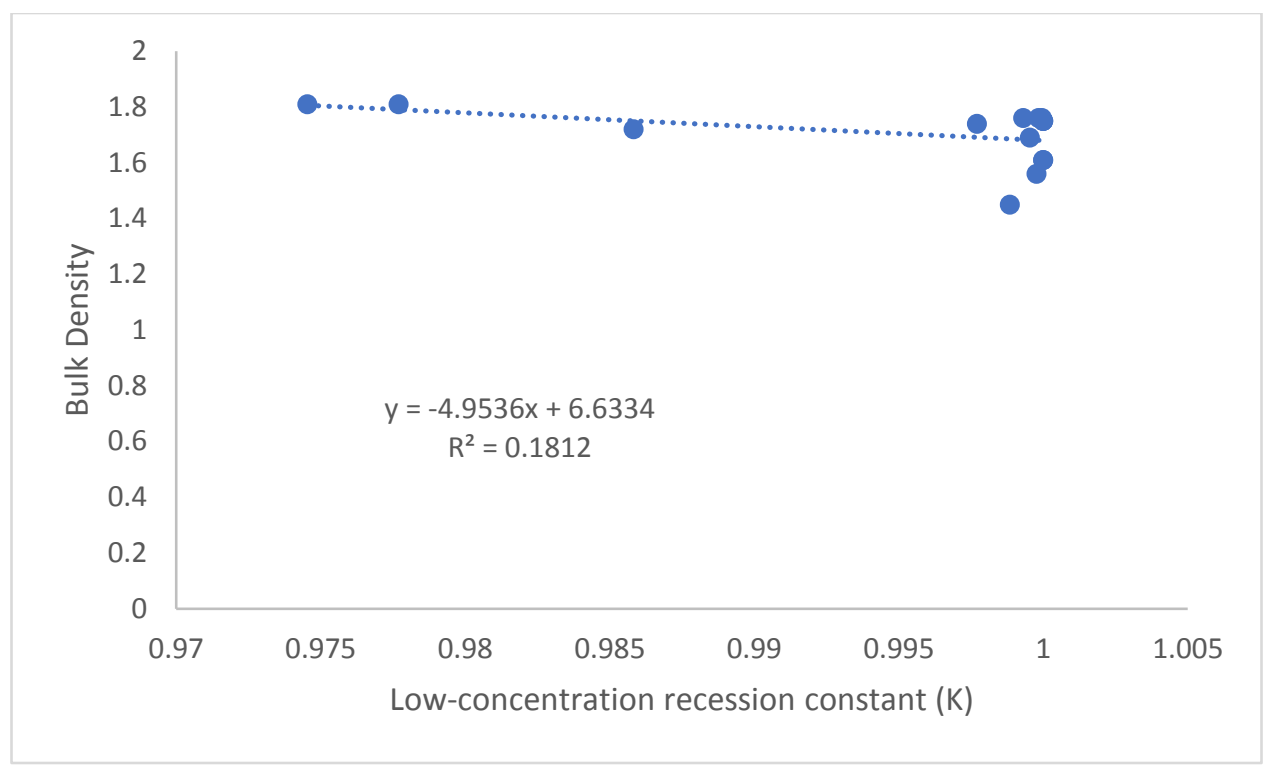

Figure 20: Bulk density of soils versus the low-concentration recession constant.

\section{DISCUSSION AND CONCLUSION}

A collection of subsurface contaminant studies was examined to reveal trends relating long term elution tailing behavior with porous media characteristics, particularly the soils' organic carbon content. The goal of the recession curve analysis was to find the low-concentration recession constant, $\mathrm{K}$, as a function of contaminant concentration over time or space. The $\mathrm{K}$ values found here ranged from 0.9745407 to 0.9999988 . There is the question of why the K values found here are so close to each other, all nearly 1 . There is no existing research regarding $\mathrm{K}$ available for comparison; therefore, it is unknown whether that trend is to be expected. It was not expected that regardless of fines content, organic carbon content, porosity, bulk density, or equilibrium distribution of contaminant the media exhibited similar K. The relationship between porosity, $\mathrm{F}_{\mathrm{oc}}$, fines fraction and $\mathrm{K}$ is increasing; higher values of these soil properties are generally associated with greater $\mathrm{K}$ values, see Figures 16,18 , and 19. Bulk density and $\mathrm{K}_{\mathrm{d}}$ exhibit a decreasing relationship with K, as seen in Figures 17 and 20.

The $\mathrm{R}^{2}$ values generated from linearly regressing the data ranged widely from 0.12494 to 0.9542 . This sets with weak correlation could be a function of data quality or data density. Each study provided a limited number of data points in the elution tailing zone; higher density data in this stage of dispersion would be preferred for further analysis. This research should be validated or 
rejected through additional research with more rigorously collected data. Selection of coordinates is too prone to error and imprecise to glean robust results. Overall trends may be regarded as starting points for further examination. If the experiment was replicated, the data should be acquired form the original researchers. Precision in data is critical, and it is difficult to spot errant data when it is already unreliable. 


\section{Works Cited}

Brusseau, M.L., Russo, A.E., Schnaar, G. (2012). "Nonideal transport of contaminants in heterogeneous porous media: 9 Impact of contact time on desorption and elution tailing." Chemosphere, 89, 287-292.

Culver, T.B., Hallisey, S.P., Sahoo, D., Deitsch, J.J., Smith, J.A. (1997). “Modeling the Desorption of Organic Contaminants from Long-Term Contaminated Soil Using Distributed Mass Transfer Rates.” Environmental Science \& Technology, 31(6), 15811588.

Fetter, C.W. (1993). Contaminant Hydrogeology. New York, New York.

Johnson, G.R., Zhang, Z., Brusseau, M.L. (2003). "Characterizing and quantifying the impact of immiscible-liquid dissolution and nonlinear, rate-limited sorption/desorption on lowconcentration elution tailing." Water Resources Research, 39(5).

Johnson, G.R., Zhang, Z., Brusseau, M.L. (2009). "Mass Removal and low-concentration tailing of trichloroethylene in freshly-amended, synthetically-aged, and field-contaminated aquifer material." Chemophere, 75, 542-548.

Russo, A. Johnson, G.R., Schnaar, G., Brusseau, M.L. (2010). "Nonideal transport of contaminants in heterogeneous porous media: 8 . Characterizing and modeling asymptotic contaminant-elution tailing for several soils and aquifer sediments." Chemosphere, 81, 366-371.

Thorbjarnarson, K.W., Mackay, D.M. (1996). “A field test of tracer transport and organic contaminant elution in a stratified aquifer at the Rocky Mountain Arsenal (Denver, Colorado, U.S.A.).” Journal Contaminant Hydrology, 24, 287-312. 